\title{
Take my breath away: a case of lactic acidosis in an asthma exacerbation
}

\author{
Reid McGonigle, MD*; Robert A. Woods, $\mathrm{MD}^{\dagger}$
}

\section{ABSTRACT}

A 36-year-old male with a history of chronic asthma presented to an emergency department with shortness of breath consistent with an asthma exacerbation. He had persistent tachypnea following inhaled bronchodilator treatment; thus, the workup and differential diagnosis were expanded. He was found to have a mixed respiratory alkalosis and metabolic acidosis with elevated serum lactate without an obvious cause and was admitted to hospital. His case was reviewed, and the lactic acidosis was thought to be caused by inhaled $\beta_{2}$-agonist use. Emergency physicians should be aware of the potential side effects of inhaled $\beta_{2}$-agonists as lactic acidosis may complicate clinical assessment and management of asthma exacerbations and lead to unnecessary and potentially dangerous escalations in therapy.

\section{RÉSUMÉ}

Un patient de sexe masculin de 36 ans ayant de antécédents d'asthme chronique s'est présenté aux urgences et affichait des difficultés respiratoires compatibles avec une aggravation de l'asthme. II présentait une tachypnée persistante à la suite d'un traitement au bronchodilatateur en inhalation; ainsi, le bilan et le diagnostic différentiel ont été élargis. II s'est avéré qu'il avait une alkalose respiratoire et une acidose métabolique mixte accompagnée d'une élévation de lactates sériques sans cause évidente, et il fut admis à I'hôpital. Son cas fut examiné, et on a établi que l'acidose lactique était due à l'emploi d'un agoniste b2 en inhalation. Les urgentologues devraient être au courant des effets secondaires possibles des agonistes b2 inhalés, car l'acidose lactique peut compliquer l'évaluation clinique, et la prise en charge de l'aggravation de l'asthme, et conduire à une augmentation inutile et potentiellement dangereuse du traitement.

Keywords: asthma, $\beta_{2}$-agonist, lactic acidosis, metabolic acidosis, salbutamol

Asthma is a common emergency department (ED) presentation, treated in most cases with corticosteroids, salbutamol, and ipratropium bromide (IB). $\cdot^{1-3}$ This case report describes a mild to moderate asthma exacerbation complicated by lactic acidosis and respiratory alkalosis. Although arterial blood gas (ABG) abnormalities are not uncommon in asthma exacerbations in the ED, elevated serum lactate is less common, particularly in mild presentations. We review the literature surrounding elevated lactate associated with asthma exacerbations and discuss the potential etiologies of this association, including the underrecognized complications of inhaled $\beta_{2}$-agonist therapy.

\section{CASE REPORT}

A 36-year-old male with a history of asthma arrived via ambulance at an ED at 12:35 with a chief complaint of shortness of breath. His vital signs at triage were temperature $=36.2^{\circ} \mathrm{C}\left(97.1^{\circ} \mathrm{F}\right)$; heart rate $=108$ beats $/ \mathrm{min}$; blood pressure $=137 / 74 \mathrm{~mm} \mathrm{Hg}$; respiratory rate $=28$ breaths $/ \mathrm{min}$; and $\mathrm{O}_{2}$ saturation $=99 \%$ on room air. He was triaged as a CTAS (Canadian Triage and Assessment Scale) level 4.

He described a 4-day history of progressive worsening shortness of breath associated with productive cough, fever and chills, and intermittent chest pains. The patient had been using a salbutamol metered-dose inhaler three to four puffs four times per day for several days. His past medical history was significant for chronic asthma and allergic rhinitis, for which he

Île-à-la-Crosse Hospital, île-à-la-Crosse, SK. †Department of Surgery, College of Medicine, University of Saskatchewan, Saskatoon, SK.

Correspondence to: Dr. Reid McGonigle, c/o Île-à-la-Crosse Hospital, Île-à-la-Crosse, Sk SOM 1CO; reid.m@usask.ca.

Submitted May 11, 2010; Revised NA; Accepted May 12, 2010.

This article has been peer reviewed. 
normally used salbutamol three times per week and fluticasone 3 days per week, although he ran out of his inhaled corticosteroid several weeks earlier. Two months earlier, he presented to an ED with a mild asthma exacerbation; however, no investigations were performed, and he received no treatment. He reported having asthma for 8 to 9 years and denied previous hospitalizations for any asthma exacerbations. He admitted to being a 60-pack-year cigarette smoker who quit 5 years previously. Neither spirometry nor pulmonary function testing had ever been performed.

His stated medical history included chronic back pain and anxiety, and his hospital chart reported bipolar affective disorder. He had no thromboembolic risk factors. He denied any substance abuse. His other medications included diclofenac $75 \mathrm{mg}$ daily, quetiapine $75 \mathrm{mg}$ as needed (PRN) at night, and acetaminophen PRN.

On examination at $13: 25$, the patient was in mild to moderate respiratory distress with a respiratory rate of 28 breaths/min. He had wheezes bilaterally. His cardiovascular and abdominal examinations were normal. His peak flow with suboptimal technique was $270 \mathrm{~L} / \mathrm{min}$ prior to any treatment (43\% of predicted).

Salbutamol $2.5 \mathrm{mg}$ and IB $250 \mu \mathrm{g}$ were administered via nebulization by staff prior to physician assessment; no treatment was given earlier by the ambulance staff. Salbutamol $5 \mathrm{mg}$ and IB $500 \mu \mathrm{g}$ were nebulized every 20 minutes for three doses, and $50 \mathrm{mg}$ oral prednisone was administered. No investigations were initially ordered.

At 16:30, his $\mathrm{O}_{2}$ saturation was $96 \%$ on room air and his wheeze had resolved; however, his respiratory rate remained at 28 to 30 breaths $/ \mathrm{min}$. The patient felt slightly better but still complained of shortness of breath. Investigations including ABG, chest radiography, and electrocardiography (ECG) were ordered. Additional doses of salbutamol and IB were ordered, as well as $2 \mathrm{~g} \mathrm{IV} \mathrm{MgSO}_{4}$ and $250 \mathrm{mg}$ oral clarithromycin. A total of $22.5 \mathrm{mg}$ of nebulized salbutamol was administered in the ED prior to blood work and an ABG being drawn.

The initial laboratory investigations at 17:42 were as follows: hemoglobin $153 \mathrm{~g} / \mathrm{L}$, white blood cell count $8.95 \times 10^{\circ} / \mathrm{L}$ with neutrophils $8.01 \times 10^{\%} / \mathrm{L}$, platelets $240 \times 10 \%$ L, international normalized ratio 1.1 , partial thromboplastin time 35 seconds, sodium $139 \mathrm{mmol} / \mathrm{L}$, chloride $103 \mathrm{mmol} / \mathrm{L}, \mathrm{CO}_{2} 20 \mathrm{mmol} / \mathrm{L}$, potassium $2.8 \mathrm{mmol} / \mathrm{L}$, glucose $11.1 \mathrm{mmol} / \mathrm{L}$, creatinine $101 \mu \mathrm{mol} / \mathrm{L}$, and anion gap 16.

The chest radiograph revealed normal lung volumes with prominent bilateral perihilar thickening, compatible with lower airway inflammation.

The ECG showed normal sinus rhythm at a rate of 87 , right axis deviation, early transition in the precordial leads, borderline right ventricular hypertrophy, and incomplete right bundle branch block.

The ABG showed a mixed acid-base disturbance with $\mathrm{pH}$ of 7.44, oxygen partial pressure $\left(\mathrm{pO}_{2}\right) 76 \mathrm{~mm}$ $\mathrm{Hg}$, carbon dioxide partial pressure $\left(\mathrm{pCO}_{2}\right) 27 \mathrm{~mm}$ $\mathrm{Hg}$, bicarbonate $18 \mathrm{mmol} / \mathrm{L}$, and lactate $5.3 \mathrm{mmol} / \mathrm{L}$ (Table 1). Based on the elevated lactate, antibiotic coverage was broadened to cefotaxime $1 \mathrm{~g}$ IV for possible occult sepsis. In the presence of both a primary metabolic acidosis and a primary respiratory alkalosis (based on an expected $\mathrm{pCO}_{2}$ of $35 \mathrm{~mm} \mathrm{Hg}$ ), acetylsalicylic acid (ASA) toxicity was suspected, and an IV bicarbonate infusion with potassium supplementation was initiated at 18:45. Additional blood work and a repeat $A B G$ were ordered. Internal Medicine was consulted for further workup.

At 20:15, he was afebrile, with a heart rate of 98 beats $/ \mathrm{min}, \mathrm{O}_{2}$ saturation of $98 \%$ on room air, and respiratory rate of 24 to $30 \mathrm{breaths} / \mathrm{min}$. He appeared anxious and had difficulty speaking in complete sentences. Respiratory examination revealed minimal wheeze with good air entry bilaterally. Examinations of the head and neck and cardiovascular, abdominal, dermatologic, and peripheral systems were unremarkable.

\begin{tabular}{|c|c|c|c|c|c|c|c|}
\hline $\begin{array}{l}\text { Time from ED } \\
\text { presentation }\end{array}$ & $\mathrm{pH}$ & $\begin{array}{c}\mathrm{pO}_{2} \\
(\mathrm{~mm} \mathrm{Hg})\end{array}$ & $\begin{array}{c}\mathrm{pCO}_{2} \\
(\mathrm{~mm} \mathrm{Hg})\end{array}$ & $\begin{array}{l}\mathrm{HCO}_{3}{ }^{-} \\
(\mathrm{mmol} / \mathrm{L})\end{array}$ & $\begin{array}{l}\text { Anion } \\
\text { gap }\end{array}$ & $\begin{array}{l}\text { Lactate } \\
\text { (mmol/L) }\end{array}$ & $\begin{array}{l}\text { Glucose } \\
\text { (mmol/L) }\end{array}$ \\
\hline 5 h $10 \mathrm{~min}$ & 7.44 & 76 & 27 & 18 & 16 & 5.3 & 12.0 \\
\hline 7 h 55 min & 7.48 & 106 & 19 & 14 & 18 & 6.1 & 12.5 \\
\hline $20 \mathrm{~h} 10 \mathrm{~min}$ & 7.53 & 114 & 22 & 19 & 12 & 1.2 & 6.6 \\
\hline
\end{tabular}


The repeat $\mathrm{ABG}$ demonstrated a worsening of both his metabolic acidosis, with bicarbonate of $14 \mathrm{mmol} / \mathrm{L}$ and lactate of $6.1 \mathrm{mmol} / \mathrm{L}$, and his respiratory alkalosis, with $\mathrm{pCO}_{2}$ of $19 \mathrm{~mm} \mathrm{Hg}$ (see Table 1). Additional blood work showed aspartate aminotransferase (AST) $35 \mathrm{U} / \mathrm{L}$, creatinine kinase $191 \mathrm{U} / \mathrm{L}$, lipase $36 \mathrm{U} / \mathrm{L}$, troponin $<0.02 \mu \mathrm{g} / \mathrm{L}$, and salicylate level $<$ $0.03 \mathrm{mmol} / \mathrm{L}$. Blood culture results obtained later revealed no growth.

He was admitted to the medical ward with a diagnosis of asthma exacerbation and lactic acidosis of unknown cause. With ASA being undetectable, his bicarbonate infusion was stopped. His overnight treatment included $\mathrm{IV}$ potassium replacement and minimal $\mathrm{O}_{2}$ supplementation. He received prednisone $50 \mathrm{mg}$, clarithromycin $250 \mathrm{mg}$, and diclofenac-misoprostol $75 \mathrm{mg}$. He had salbutamol $2.5 \mathrm{mg}$ with IB by nebulization at midnight and salbutamol $5 \mathrm{mg}$ at 06:00.

The next morning, the $\mathrm{ABG}$ on $1 \mathrm{~L} \mathrm{O}_{2}$ revealed a persistent respiratory alkalosis with $\mathrm{pH} 7.53$ and $\mathrm{pCO}_{2}$ $22 \mathrm{~mm} \mathrm{Hg}$. The bicarbonate increased to $19 \mathrm{mmol} / \mathrm{L}$; the serum lactate and glucose decreased to $1.2 \mathrm{mmol} / \mathrm{L}$ and $6.6 \mathrm{mmol} / \mathrm{L}$, respectively (see Table 1). Complete blood count, electrolytes, and renal function values were all within normal limits. No recorded vital signs or physical examination findings were available in the chart from the morning. The patient was discharged home with a prescription for IB inhaler twice a day, clarithromycin for 10 days, and salbutamol PRN. He was instructed to follow up with his family doctor.

\section{DISCUSSION}

Shortness of breath owing to asthma exacerbation is among the most common presentations in Canadian EDs. Physician-diagnosed asthma affects approximately 3 million Canadians, and asthma is a major cause of hospitalization, particularly in children. ${ }^{1}$ In the United States, there are approximately 1.8 million ED visits annually for acute asthma. In Canada, asthma patients who present to the ED with exacerbations represent a poorly controlled group; $51 \%$ report unscheduled visits related to their asthma, and 30\% report one or more visits to the ED within the past year. ${ }^{2}$ A recent publication reports that an adult asthmatic visits an ED every 30 minutes in Alberta. ${ }^{3}$ The total costs of asthma in Canada are over $\$ 1$ billion annually, of which approximately one-quarter is related to acute care. ${ }^{4}$ Mortality rates in Canada have fallen consistently over the past 20 years. In 2001, there were 299 deaths; $5 \%$ were children, whereas $62 \%$ were adults over 70 years of age. ${ }^{5}$

We present a case of a moderately severe asthma exacerbation with persistent shortness of breath and tachypnea after initial treatment with bronchodilators. Blood gas analysis revealed a mixed acid-base disorder with an elevated lactate. In mild asthma exacerbations, ABGs are not indicated; however, when obtained, the results are either normal or demonstrate a simple respiratory alkalosis. In one study of adults with acute asthma in the ED with more evidence of outflow obstruction and hypoxia than our patient had, isolated respiratory alkalosis was present in almost half of the patients, whereas a mixed metabolic acidosis with respiratory alkalosis was present in only $6.1 \%$ of the patients. ${ }^{6}$

Lactic acidosis may be classified as either type A or B. Type A occurs with tissue hypoperfusion; precipitating conditions include systemic shock, carbon monoxide poisoning, or even intense exercise. Type $\mathrm{B}$ lactic acidosis is a result of altered cellular function, which either increases the conversion of pyruvate to lactate or decreases lactate metabolism. This may result from inborn errors of metabolism, liver failure, or metabolic changes induced by medications or toxins.

Lactic acidosis has been well described in severe asthma exacerbations in adults and children. Causative hypotheses have included tissue hypoxia, excessive respiratory muscle use, and/or altered liver metabolism; however, it has become increasingly accepted that it is primarily an effect of $\beta_{2}$-agonist use. ${ }^{7-11}$ Although the mechanism is not completely understood, $\beta_{2}$ agonists are known to stimulate cyclic adenosine monophosphate (cAMP)-mediated glycogenolysis and lipolysis. Hyperglycemia and free fatty acid inhibition of pyruvate dehydrogenase lead to anaerobic metabolism of pyruvate to lactate. ${ }^{9,11,12}$ Some researchers have postulated that hyperadrenergic states, owing to endogenous catecholamine release secondary to respiratory distress and/or anxiety, and cotreatment with corticosteroids predispose patients to lactic acidosis with the administration of $\beta_{2}$-agonists. ${ }^{10,13} \beta_{2^{-}}$ Agonist-induced lactic acidosis has most often been reported in severe asthma exacerbations treated with intravenous therapy; however, there are case reports of patients treated with inhaled therapy alone., ${ }^{71-19}$ The prevalence of lactic acidosis has been reported between 
16 and $40 \%$ in severe asthma exacerbations, more commonly in the intensive care unit setting than in the ED. ${ }^{13}$ It remains unclear, however, if lactic acidosis is a marker of asthma severity in this setting or if it is iatrogenic. One recent ED-based prospective study demonstrated hyperlactatemia shortly following inhaled salbutamol therapy and suggested that it is likely underrecognized in the ED. ${ }^{13}$

Inhaled bronchodilators are a mainstay of ED asthma management regardless of the severity. ${ }^{20}$ In addition to bronchodilation, commonly seen effects include mild tachycardia and tremor. However, less obvious adverse effects are well documented in the literature and may have a deleterious effect on patient management and outcomes. For emergency physicians, reactive airway disease pathophysiology and medicationinduced alterations in cellular metabolism have very real clinical implications. Salbutamol-induced lactic acidosis may complicate clinical assessment and management of asthma exacerbations in the ED. Persistent tachypnea, which usually indicates persistent airway obstruction but may indicate respiratory compensation of metabolic acidosis, commonly leads to increased doses of salbutamol. Increased minute ventilation decreases expiration time and increases dead space, leading to $\mathrm{CO}_{2}$ retention and decreased cardiac output in severe cases. ${ }^{21}$ Metabolic acidosis and hypokalemia may further contribute to cardiorespiratory decompensation and even failure.
Serum lactate has become a critical screening tool in the ED, especially for sepsis. Rivers's Early GoalDirected Therapy in the Treatment of Severe Sepsis and Septic Shock used systemic inflammatory response syndrome (SIRS) criteria (including tachycardia and tachypnea, which our patient had on presentation) plus hypotension or a lactate $>4 \mathrm{mmol} / \mathrm{L}$ as inclusion criteria. ${ }^{22}$ Asthmatics are not immune to sepsis, and an elevated lactate puts physicians in a diagnostic and treatment dilemma. As elevated serum lactate is an important marker of tissue hypoxia and hypoperfusion in critically ill patients and a marker of poor prognosis, its presence in an asthma exacerbation requires very careful attention.

\section{CONCLUSION}

Our case is an example of lactic acidosis in a relatively moderately severe asthma exacerbation that complicated patient management and disposition. We suspect that the metabolic effects were induced by salbutamol therapy. The presentation and workup did not reveal any other cause for the acidosis. Concomitant hyperglycemia and hypokalemia are consistent with the effects of $\beta_{2}$-agonists. Finally, the metabolic abnormalities, including the elevated lactate, resolved with decreased salbutamol use and without significant additional intervention. Our patient may have been

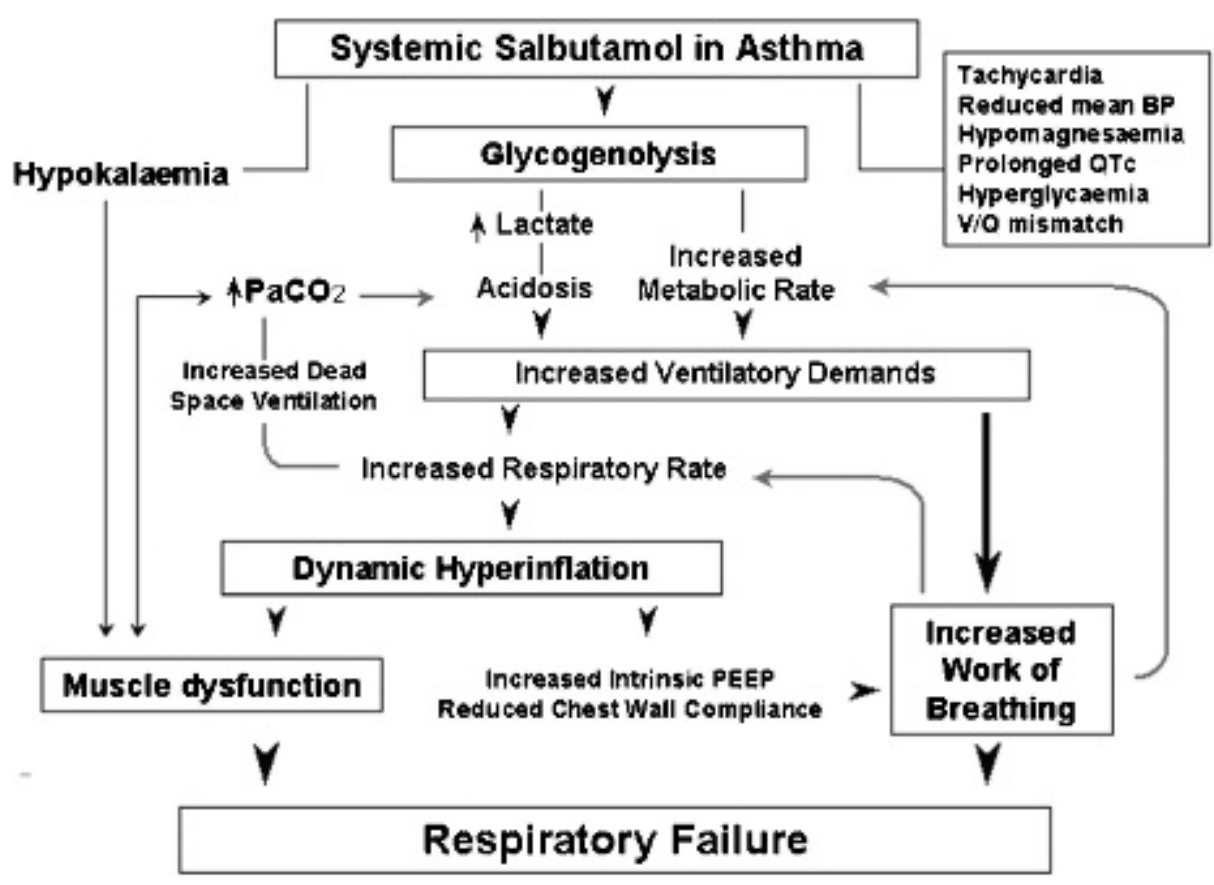

Figure 1. Clinical implications of systemic salbutamol. Reproduced with permission from Tobin A. ${ }^{21}$ $\mathrm{PaCO} 2=$ arterial carbon dioxide tension; PEEP = peak end-expiratory pressure. 
sensitive to the effects of salbutamol owing to his anxious state; this may account for the persistent respiratory alkalosis prior to discharge from the ward.

Although $\beta_{2}$-agonist-induced lactic acidosis has been described, our case is unique in the literature given the severity of the disease and the relatively low doses of exclusively inhaled salbutamol. The existing literature does not offer any evidence-based recommendations for clinicians who may encounter this scenario. Future research should be directed toward identifying which patients may be predisposed to this phenomenon and determining what should be done when there is a clinical need for bronchodilation in an asthma exacerbation complicated by lactic acidosis. Emergency physicians should be aware of the underrecognized potential of inhaled salbutamol to complicate the management of asthma exacerbations.

Competing interests: None declared.

\section{REFERENCES}

1. Life and breath: respiratory disease in Canada. Ottawa (ON): Public Health Agency of Canada; 2007. Available at: www.phacaspc.gc.ca/publicat/2007/lbrdc-vsmrc/index-eng.php (accessed Oct 6, 2009).

2. Rowe BH, Villa-Roel C, Abu-Laban RB, et al. Admission to Canadian hospitals for acute asthma: a prospective, multicenter study. Can Respir 7 2010;17:25-30.

3. Rowe BH, Voaklander DC, Wang D, et al. Asthma presentations by adults to emergency departments in Alberta Canada: a large population-based study. Chest 2009; 135:57-65.

4. Kaplan AG, Balter MS, Bell AD, et al. Diagnosis of asthma in adults. CMA7 2009. DOI: 10.1503/cmaj.080006.

5. Chen Y, Johansen H, Thillaiampalam S, et al. Asthma. Health Rep 2005;16(2):45-8.

6. Mountain R, Heffner J, Bracjett N, et al. Acid-base disturbances in acute asthma. Chest 1990;98:651-5.

7. Manthous CA. Lactic acidosis in status asthmaticus: three cases and review of the literature. Chest 2001;119:1599-602.
8. Braden GL, Johnson SS, Germain MJ, et al. Lactic acidosis associated with the therapy of acute bronchospasm. $N$ Engl 7 Med 1985;313:380.

9. Phillips PJ, Vedig AE, Jones MG, et al. Metabolic and cardiovascular side effects of the beta-2 adrenoceptor agonists salbutamol and rimiterol. $\mathrm{Br} f \mathrm{Clin}$ Pharmacol 1980;9:483-91.

10. Maury F, Ioos V, Lepecq B, et al. A paradoxical effect of bronchodilators. Chest 1997;111:1766-7.

11. Meert KL, Clark J, Sarnaik AP, et al. Metabolic acidosis as an underlying mechanism of respiratory distress in children with severe acute asthma. Pediatr Crit Care Med 2007;8:51923.

12. Haffner CA, Kendall MJ. Metabolic effects of beta-2 agonists. 7 Clin Pharm Ther 1992;17:155-64.

13. Rodrigo GJ, Rodrigo C. Elevated plasma lactate level associated with high dose inhaled albuterol therapy in acute severe asthma. Emerg Med 7 2005;22:404-8.

14. Prakash S, Mehta S. Lactic acidosis in asthma: report of two cases and review of the literature. Can Respir 7 2002;9:203-8.

15. Gomez Bustos MD, Garcia Ron A, Ibarra de la Rosa I, Pérez Navero JL. Lactic acidosis following high-dose inhaled salbutamol. An Pediatr (Barc) 2008;69:586-7.

16. Gonzalez Jimenez D, Concha Torre A, Menendez Cuervo S, García Hernández I. Lactic acidosis secondary to inhaled salbutamol in children with acute severe asthma. An Pediatr (Barc) 2009;71:82-3.

17. Stratakos G, Kolomenidis J, Routsi C, et al. Transient lactic acidosis as a side effect of inhaled salbutamol. Chest 2002; 122:385-6.

18. Creagh-Brown B, Ball J. An under-recognized complication of treatment of acute severe asthma. Am 7 Emerg Med 2008; 26:514.e1-3.

19. Jee R, Brownlow H. Hyperlactaemia due to nebulised salbutamol. Anaesthesia 2007;62:744-55.

20. Hodder R, Lougheed D, Rowe BH, et al. Management of acute asthma in adults in the emergency department: nonventilatory management. CMA7 2010;182:E55-67.

21. Tobin A. Intravenous salbutamol: too much of a good thing? Crit Care Resusc 2005;7:119-27.

22. Rivers E, Nguyen B, Havstad S, et al. Early goal-directed therapy in the treatment of severe sepsis and septic shock. $N$ Engl $\mathcal{F}$ Med 2001;345:1368-77. 